\title{
Eyes, ears, or nose? Comparison of three non-invasive methods to survey wolf recolonisation
}

\author{
Gabriele Cozzi ${ }^{1} \cdot$ Laura Hollerbach $^{2} \cdot$ Stefan M. Suter $^{3} \cdot$ Tobias E. Reiners $^{2} \cdot$ Florin Kunz $^{4} \cdot$ Federico Tettamanti $^{5}$. \\ Arpat Ozgul ${ }^{1}$
}

Received: 22 April 2021 / Accepted: 4 August 2021 / Published online: 3 September 2021

(C) The Author(s) 2021

\begin{abstract}
The development and use of cost-effective and appropriate survey methods to assess species distribution and to monitor range expansion and contraction of wild populations is crucial due to the limited financial resources for conservation. Of particular importance, yet little studied, is the ability to collect information before a wild population is well established, i.e. at the early stages of recolonisation. During 2018 and 2019, we used camera traps, audio recorders, and scat detection dogs simultaneously to investigate composition, detection probability, and territorial extent of a pack of wolves in the Swiss Alps. We compared the efficacy of these survey methods by assessing sampling effort, data obtained, and costs. We show that, under the presented setup, camera traps and scat detection dogs substantially outperformed audio recorders in detecting wolves, representing the packs' territorial extent, and revealing the number of adult wolves. The detection dogs did not detect pups but, unlike the other methods, allowed the identification of single individuals. The use of four camera traps during 13 weeks, a 24-km-long transect walked with the detection dog, or the use of one audio recorder during 148 weeks were necessary to obtain a comparable wolf detection probability. Our results show that no single method was able to return all information that we hoped to collect. Comprehensive and cost-effective information was best obtained by combining data from camera traps and detection dogs. We suggest both methods to be simultaneously used to successfully investigate wolf recolonisation into historical range.
\end{abstract}

Keywords Camera trapping $\cdot$ Canis lupus . Detection probability $\cdot$ Non-invasive survey methods $\cdot$ Occupancy $\cdot$ Passive howling $\cdot$ Recolonisation $\cdot$ Scat detection dog $\cdot$ Survey effort and costs $\cdot$ Wildlife management $\cdot$ Wolf

Handling editor: Laura Iacolina.

Gabriele Cozzi

gabriele.cozzi@uzh.ch

1 Department of Evolutionary Biology and Environmental Studies, University of Zurich, Winterthurerstrasse 190, CH-8057 Zürich, Switzerland

2 Conservation Genetics Group, Senckenberg Research Institute and Natural History Museum Frankfurt, Clamecystraße 12, 63571 Gelnhausen, Germany

3 Institute of Natural Resource Sciences, School of Life Sciences and Facility Management, Schloss, CH8820 Wädenswil, Switzerland

4 KORA Foundation, Thunstrasse 31, CH-3074 Muri, Switzerland

5 Dipartimento del Territorio, Ufficio della Caccia e della Pesca, via Franco Zorzi 13, CH-6500 Bellinzona, Switzerland

\section{Introduction}

The first 2 decades of the twenty-first century have shown radical changes in the population trends of several carnivore species. In the northern hemisphere, we assisted to population expansion and consequent recolonisation of vast areas of continental Europe and North America by wolves (Canis lupus), brown, and black bears (Ursus arctos, U. americanus) and lynx (Lynx lynx) (Chapron et al. 2014; Milanesi et al. 2017). On the other end, in the southern hemisphere, Africa is losing its lions (Panthera leo), cheetahs (Acynoxix jubatus) and leopards (P. pardus) at an unprecedented rate (Bauer et al. 2015; Jacobson et al. 2016; Durant et al. 2017). For instance, lions are projected to locally suffer a $50 \%$ decline over the next 2 decades (Bauer et al. 2015). Such changes call for the development, evaluation, and use of appropriate cost-effective techniques to assess species distribution and abundance, and to monitor their range 
expansion and contraction speed. This knowledge is vital to equip decision makers with timely and robust information needed to develop a series of evidence-based management plans and conservation strategies under the constraints of limited and constantly diminishing financial resources.

Several survey techniques have been developed and successfully used for different carnivore species and under a variety of conditions (Harrington and Mech 1982; Karanth and Nichols 1998; Long et al. 2007a, b; Funston et al. 2010; Cozzi et al. 2013; Hollerbach et al. 2018). For instance, camera trapping has been used to estimate tiger (P. tigris) densities in India (Karanth and Nichols 1998) and assemblages of mammal communities in Africa (Rich et al. 2016). Howling surveys have been used to census wolves in North America and Europe (Harrington and Mech 1982; Passilongo et al. 2015). More recently, detection dogs, whose remarkable sense of smell has long been used for civil, intelligence and military purposes, have also been used in wildlife research (Long et al. 2007a, b; Vynne et al. 2011; Becker et al. 2017; Hollerbach et al. 2018). Despite these survey techniques being increasingly used, fewer studies have sought to assess which technique performs better under given circumstances by simultaneously assessing and quantifying data quality and sampling effort. In 2018 we performed a preliminary search through the SCOPUS database of articles published since 2000. We found that no articles were published that simultaneously considered and evaluated camera trapping, passive howling surveys, and detection dogs; twenty articles were published that simultaneously considered any combination of two of the three methods; over one thousand articles were found that relied on one of the three methods without any assessment of their performance compared to other methods.

Camera trapping, passive howling surveys, and detection dogs have widely been used in wolf monitoring and research (Nowak et al. 2007; Wasser et al. 2011; Galaverni et al. 2012;), yet the three techniques differ substantially in the type of data that they can generate and in the survey effort they require. Camera traps and audio recorders may be placed and left to automatically and continuously collect data over longer periods of time, while the use of a dog requires daily employment of a search team (i.e. dog and handler) and is, therefore, usually of shorter duration. Camera traps and audio recorders may, however, suffer from theft, malfunctioning, damage, power shortage, storage capacity limits, thus reducing the effective duration during which units are successfully deployed (Meek et al. 2019; this study). Successful scat collection may, instead, be dependent on dog individual skills and environmental factors (Smith et al. 2005; Reed et al. 2011), and injuries may also impact fieldwork. Readiness of data availability from camera traps and audio recorders depends much on the frequency at which units are monitored and data downloaded and on the amount of data collected and its relative processing time. In contrast, presence data collected with the use of dogs are readily available (Long et al. 2007a, b). Furthermore, for a species like the wolf, camera traps only rarely allow individual identification (Galaverni et al. 2012; Mattioli et al. 2018), while this is possible with audio recorders and detection dogs, provided good quality of recorded howls and fresh-enough scats for DNA analysis, respectively (Rutledge et al. 2009; Root-Gutteridge et al. 2014).

Last but not least, while these techniques have been used to assess distribution, abundance, and behaviour in wellestablished populations (Long et al. 2007a, b; Galaverni et al. 2012; Brennan et al. 2013; Mattioli et al. 2018), it remains to be determined how they perform at very low densities before a population is well established-i.e. when only few scattered resident packs or individuals are present. For instance, howling, which is used for both intra- and intergroup communication (Harrington and Mech 1979), may change in the absence of neighbouring groups thus influencing detection. Moreover, for a territorial species like the wolf, ranging behaviour and chemical signalling change depending on the presence of neighbouring packs (Peters and Mech 1975), which may influence camera trapping output and the detection of faeces by detection dogs. The ability to cost-effectively monitor range expansion before a population is well established is, however, crucial to anticipate conflicts between humans and wildlife, to develop and adopt measures to maintain a positive attitude towards wildlife, and to launch information and awareness campaigns (Behr et al. 2017).

The expanding wolf population in Switzerland offers favourable conditions to investigate cost-effectiveness of different survey techniques for wolves living at low densities. Over the past 2 decades, wolves have made their reappearance in Switzerland, mainly along the Alpine mountain range (Behr et al. 2017; Stiftung KORA 2020). In 2018, when this study started, five resident packs were known across Switzerland, mainly through opportunistic sightings and discovery of predated animals, and the deployment of some camera traps; the overall population was estimated to be in excess of 40 individuals, and growing (Stiftung KORA 2020). Perceived and actual interference with human activities, and particularly predation on sheep and goats, has caused a heated debate countrywide (Behr et al. 2017; Hunziker et al. 2001). Despite the wolf has become a major topic in Switzerland, data collection is not systematic at the national level, and regional authorities have been using different methods to gather information (Dufresnes et al. 2019; Roder et al. 2020).

During 2018 and 2019, we simultaneously used camera traps, audio recorders and detection dogs to monitor a resident pack of wolves known to have been successfully reproducing since 2015 in the southern Swiss Alps (Behr 
et al. 2017; Stiftung KORA 2020). Comparison between the methods included calculation of detection probability, as well as the ability to provide information on pack territorial extent and pack size, to detect the presence of pups, and to recognize single individuals. We further compared methods assuming varying survey efforts. To quantify survey efforts, we considered manpower hours, duration of data collection, and equipment costs. We did not attempt to quantify personnel salaries as those may change considerably among countries or if volunteer-based workforce is used.

\section{Materials and methods}

\section{Study area}

This study was conducted during 2018-2019 in the Swiss Alps, along the border between the Cantons of Ticino and Graubünden. The study area, which was centred at $9.107^{\circ}$ East and $46.158^{\circ}$ North, spanned a total of $68.4 \mathrm{~km}^{2}$ of alpine landscapes situated between $2^{\prime} 237 \mathrm{~m}$ asl and the lower limit set at 1'200 m asl (Fig. 1). The landscape is characterized by rugged terrain, deep valleys, and steep cliffs, and over half of the study area has slopes $>75 \%$ (Swiss Federal Office of Topography: www.swisstopo. admin.ch). The predominant habitat types are deciduous and coniferous forests, alpine pastures, and scree. Above ca. $1600 \mathrm{~m}$ above sea level, the study area is typically covered in snow between late November and May, below this altitude snow coverage is limited to the period
January-March (F. Tettamanti, pers. obs.). We divided the study area in seven adjacent valleys following the hydrological topography of the territory; the area of each valley was roughly $10 \mathrm{~km}^{2}\left(\min 7.55 ; \max =11.54 \mathrm{~km}^{2}\right)$. In each valley, we ran $10-\mathrm{km}$-long transects with trained scat detection dogs and placed four camera traps and one audio recorder (see below for more details, Fig. 1).

Wolves have been extirpated from Switzerland and the study area for over a century. Only very recently, the study area has been partly recolonized by a pack of wolves that has established and has been reproducing since 2015 (Behr et al. 2017; Stiftung KORA 2020). Opportunistic sightings and discovery of predated animals by the Italian authorities suggest that part of the pack's territory expands on Italian territory, for which we had no access and research capabilities. No other resident packs have inhabited the surroundings in recent years and no neighbouring packs were known to be present during the duration of this study (Agency for Hunting and Fishing of the Canton of Ticino). Nomadic wolves may have, however, moved through the region. All major prey species including red deer (Cervus elaphus), roe deer (Capreolus capreolus), chamois (Rupicapra rupicapra), and wild boar (Sus scrofa) inhabit the study area (Agency for Hunting and Fishing of the Canton of Ticino: www.ti.ch). Cattle farming and to a lesser extent goat and sheep farming activities are present across the study area. Other human activities include recreational outdoor activities (mostly defined trails) and ungulate trophy hunting during three weeks in September and 2 weeks in November/December.
Fig. 1 The study area in the cantons of Ticino and Graubünden, Switzerland. The study area has been divided in seven adjacent valleys (white polygons) following hydrological topography. To obtain information on wolf presence, camera traps (red circles) and audio recorders (blue triangles) have been placed in each valley, and transects walked with a trained scat detection dog (green lines). Valleys (from left to right): Roveredo, Arbedo, Morobbia, Valletta, Leveno, Serdena, Valcolla. The yellow line represents the boundary with Italy

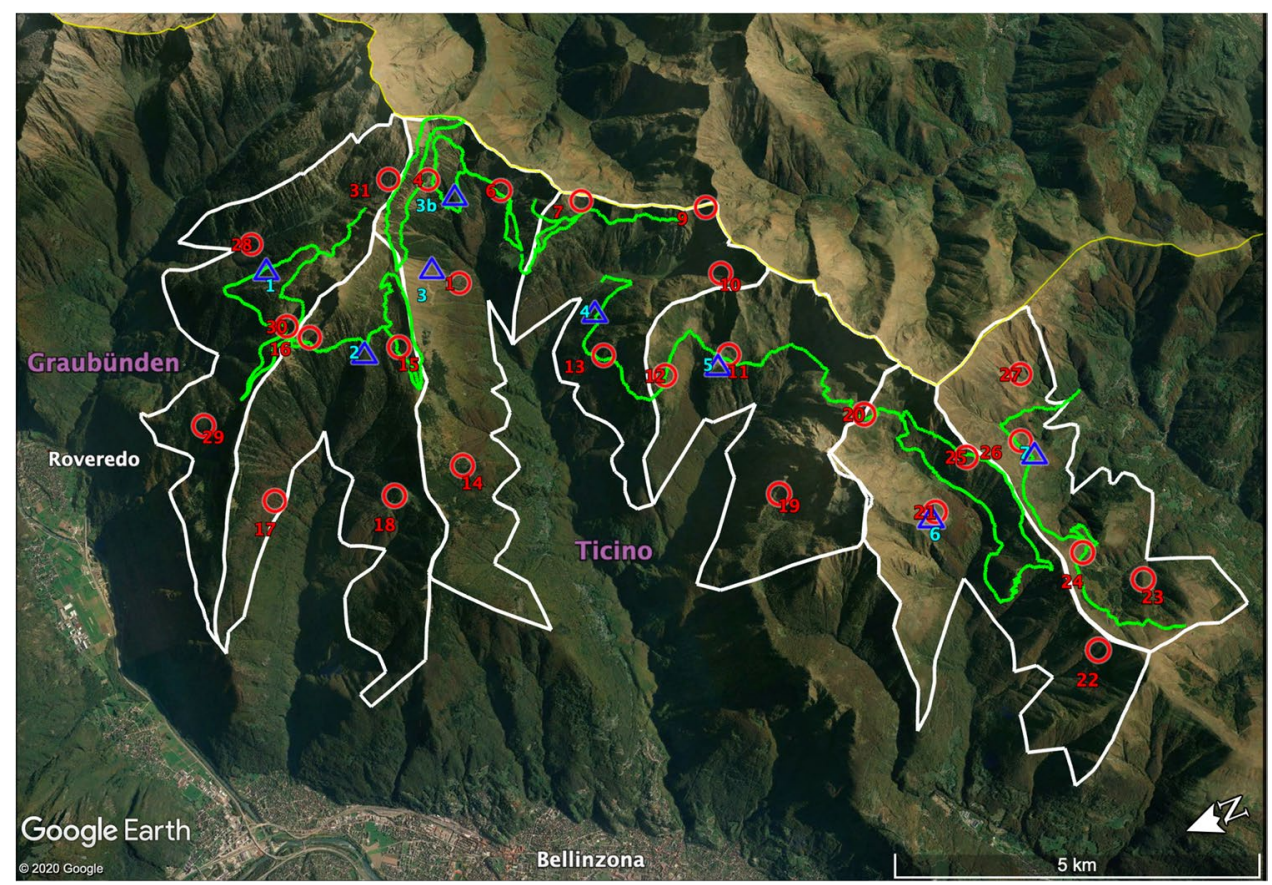




\section{Survey methods}

We used three non-invasive survey methods, namely camera trapping, passive howling, and scat detection dogs to detect wolf presence across the study areas.

\section{Camera trapping}

We placed four camera traps (Cuddeback C123 or Cuddeback Professional Color, Green Bay, USA) in each valley to have one camera every $2-2.5 \mathrm{~km}^{2}$, as previously suggested (TEAM 2011; Clare et al. 2015). Due to the malfunctioning and thus shortage of one camera, one camera (nr. 20, Fig. 1) was shared between two valleys. Due to logistic constraints, one camera could not be deployed in the Leveno valley in 2018. Within the constraints imposed by the network of hiking trails, we chose locations to ensure even valley coverage. We placed cameras along hiking trails at a distance $\geq 1 \mathrm{~km}$ of each other. In both years, we deployed cameras in late May/ beginning of June and removed them at the end of October/ beginning of November. We set cameras to continuously record during day and night; to trigger five times in fast sequences at each detection event; to allow 1-s recovery time between detection events during daytime and $2 \mathrm{~s}$ at night. On average, a set of 8 AA batteries (Duracell AA Plus Power or Energizer AA Max Power) and a 32 GB SanDisk memory card were sufficient to power the cameras for the entire deployment (5 months each year). Cameras were checked at irregular intervals to ensure correct functioning; such intervals depended on the activity of wildlife rangers (for purposes other than camera trapping) in the vicinity of a given camera.

During the same period, we placed additional cameras (four in 2018 and three in 2019) in the Morobbia valley (Fig. 1) where the pack had pups during the summers 2015-2017. These cameras were placed by wildlife rangers where, according to information at their disposal (e.g. sightings, tracks), the chance of detecting wolves was the highest, and served to crosscheck the performance of the randomly placed cameras.

Wildlife rangers manually screened all pictures and extracted and catalogued those with wolves according to date and camera ID. Rangers annotated the number of wolves in each frame, where possible divided by age (i.e. adults and pups), as a means to infer minimum pack size. Minimum pack size was also inferred based on a series of pictures in rapid sequence of wolves unambiguously moving in a single file. For each camera, we used pictures collected during a week as our replicates. For each replicate, wolves were either photographed at least once (1) or not (0). The weekly composite information from the four cameras placed in each of the seven valleys represented our valley-specific detection history.

\section{Passive howling}

We placed one audio recorder (Songmeter SM3, WildLife Acoustics Inc., USA) in each valley. Based on expected howl detectability of $>3 \mathrm{~km}$ (Suter et al. 2017), we deemed one audio recorder to be suitable to cover a large portion of a valley. We chose locations with the two criteria of easy accessibility and largest coverage potential according to the topography. We did not place audio recorders on mountain ridges between two valleys to ensure that each recorder would only record howls in one valley. We fixed sound-recorders on tree trunks or poles $1.5-2 \mathrm{~m}$ high. In both years, we deployed audio recorders in late May/beginning of June and removed them at the end of October/November. We programmed the sound-recorders to record from $6 \mathrm{pm}$ to $6 \mathrm{am}$ to get $12 \mathrm{~h}$ recording per night, the main howling time (Suter et al. 2017). We used the following parameters: sampling rate $8000 \mathrm{~Hz}$, bit rate 16-bit, microphone gain $+50 \mathrm{~dB}$, recording format mono. In 2018, monthly checks were necessary to change batteries (Energizer LR20 Energizer MAX D or Varta LR20 VARTA Longlife Power D) and memory cards (SanDisk with 32 GB and 64 GB capacity). In 2019, we used solar panels and external batteries (Spypoint Battery Kit $12 \mathrm{~V}$ and Spypoint solar panel SP-12 V) for continuous power supply. For each sound-recorder, we used calls collected during a week as our replicates. For each replicate, wolves were either detected at least once (1) or not (0), forming our valley-specific detection history. In both years, we placed one additional audio recorder in the Morobbia valley, near the 2015-2017 breeding burrow, to cross-check the performance of the randomly placed audio recorder in that valley.

We used an automated, artificial intelligence-based Wolf Detection Algorithm (WDA) developed in collaboration between the Zürich University of Applied Sciences (www. zhaw.ch) and the Swiss-based Company Busino (www. busino.ch) to identify wolf howls from the sound recordings. The WDA, which works in a conservative fashion (i.e. is biased towards false positives), pulls candidate sequences of possible howling events from entire recording files and subsequently saves them as JPEG spectrograms. We then manually inspected each candidate spectrogram sequence using the software Raven Lite 2.0 (Lab of Ornithology, Cornell University, USA) to confirm a wolf howl events. A sequence was either scored as a howling event or discarded (Suter et al. 2017) and, when applicable, the number of individuals noted. Following Passilongo et al. (2015), we determined the minimum number of howling individuals and the presence of pups by counting howls visible simultaneously in the spectrogram (Supplementary Material S1). We assigned to the same event wolf howls that were less than 5 min apart. Howling start and end time were determined on 
the basis of the JPEG spectrogram sequence (Supplementary Material S1).

\section{Scat detection dog}

In each valley, we designed a $10-\mathrm{km}$-long transect along hiking trails and some short sections of very little used agricultural roads (Fig. 1). We deemed this transect length to be adequate to ensure dog attentiveness and concentration along the entire transect; similar lengths were used by Clare et al. (2015) and Hollerbach et al. (2018). Where possible, we planned transects to be circular, with the start/end point being accessible by car, and to cover as much of the valley as possible. We further divided each transect in 2-km-long sections (mean $\pm \mathrm{sd}=1989 \pm 148 \mathrm{~m}$ ), which we used as our replicates. For each replicate, at least one scat was detected (1) or not (0), forming our valley-specific detection history. We conducted wolf scat searches in early summer after snowmelt (late May/June) and in autumn before snowfall (October) over 2 years, for a total of four field visits. Three trained dogs (two Labrador Retriever and one Flat Coated Retriever, all females, and $>2$ years of age) and two professional handlers (L. Hollerbach and L. Wirk), all with several years of experience in scat finding and sampling (e.g. Hollerbach et al. 2018; Hatlauf et al. 2020), searched for wolf scats. Dog 1 and its handler searched for scats in 2018 and in summer 2019. Dogs 2 and 3, led by the second handler, searched for scats in autumn 2019. Dog 1 searched with a regime of 1 day of rest every 2 or 3 days of work, while dogs 2 and 3 took daily turns. We hereafter refer to dog and handler as 'searching team'. Dog 1 searched on or off a $15 \mathrm{~m}$ leash, dogs 2 and 3 searched off leash. Due to the rugged topography and steep slopes, and because wolves are known to defecate and mark along existing paths (Peters and Mech 1975; Vilà et al. 1994; Stępniak et al. 2020), the dogs mainly moved and searched along the hiking trails or a few meters adjacent to them, irrespective of the leash. A suite of factors can influence dog accuracy (Long et al. 2007b), to keep dog fatigue to a minimum and dog detection accuracy as constant as possible, the work with the dog was as follow: 2 days of work, 1 day of rest, 3 days of work, 1 day of rest, 2 days of work, and so forth (Hurt and Smith 2009); transects were walked during the cooler morning hours; and transects lasted $<6 \mathrm{~h}$. To test dog accuracy, towards the end of each transect the dog was left to rest and a wolf scat, which was kept in an air tight glass jar, was thrown (not deposited, to reduce association with the handler smell) on the side of the transect ca. $100 \mathrm{~m}$ away from the dog and out of sight. After resuming walking the transect, the dog always indicated the scat, which we considered as a sign that dog concentration and accuracy remained constant across the entire transect.

For each scat found by the searching team, we transferred a 2-3 cm section to a DNA-free sample container (Sarstedt,
Mawson Lakes, AUS) with $30 \mathrm{ml}$ pure ethanol. Where mucus was still existent on the scat surface, it was sampled to increase the probability of successful DNA analyses (Oliveira and Duarte 2013). We stored samples protected from high temperatures and sunlight until further processing. We sent the collected samples to the Conservation Genetics Group of the Senckenberg Nature Research Society, Germany for analysis at the species level. We then sent samples that were confirmed as wolf to the Laboratory for Conservation Biology of the University of Lausanne, Switzerland for analysis at the individual level.

\section{Data analysis}

We combined information from the three survey methods to obtain the most comprehensive baseline information of the pack situation. This included obtaining information on the pack composition (number of adults and pups) and presence in each valley.

\section{Pack composition}

First, we compared the performance of each of the three survey methods in providing information on pack size by pooling information collected during 2018 and 2019 and comparing those against the baseline information. Then, to investigate how the three methods perform under different sampling regimes, we compared performances by halving survey duration and survey effort. For each year, we achieved half survey durations by separating the two field visits with the detection dogs, and considering only the first (respectively, the second) half of the 4 months data collection with the cameras and the audio recorders. We achieved half survey efforts by alternating the 2-km-long sections used as replicates with the detection dog, and alternating weeks for the data collected with the camera traps and the audio recorders. We then averaged values from the four half surveys (two in each year) to obtain one value for pack composition under the half survey duration and half survey effort regimes. We could not achieve half survey efforts by halving the number of pieces of equipment used because we only had one audio recorder and walked a single transect using one dog in each valley.

\section{Estimation of detection probability and sampling effort}

We used a two-season site occupancy model, which accounts for imperfect detection (MacKenzie et al. 2002), to estimate detection probabilities for each of the three survey methods. We pooled the data of both years in one model to achieve a better estimation of detection probability parameters. We organised data in spatial replicates (2-km-long sections) for the detection dog survey and temporal replicates (one 
week) for the camera traps and audio recorders surveys. We assumed survey method-specific detection probability $\left(p_{m}\right)$ to be constant across the valleys and the years, but allowed occupancy to vary between the years. We implemented the model in WinBUGs (Kéry and Schaub 2011) using the package R2WinBugs with 20.000 iterations, 3 chains, a burn-in of 4.000 and a thinning of 5 . The model iterated over each replicate [j], over the seven valleys (i.e. the sampling units) [i] and the 2 years [y]. For each survey method, we then calculated the probability $\left(P_{m}\right)$ to detect wolves in a valley (assuming it was occupied) as:

$P_{m}=1-\left(1-p_{m}\right)^{n_{m}}$,

where $n_{m}$ represents the average number of method-specific replicates in each valley $\left(n_{m}=20,15,5\right.$ for camera trap, audio recorder, and detection dog, respectively). After Long et al. (2007a, b), we further calculated the effect of any combination of the three survey methods on detection probability $\left(P_{\text {comb }}\right)$ in any valley as:

$P_{\text {comb }}=1-\prod_{m=1}^{M}\left(1-p_{m}\right)^{n_{m}}$,

where $M$ is the number of survey methods in the combination (i.e. either two or three). Lastly, we solved Eq. 1 to $n$ to calculate the minimum number $\left(n_{\min }\right)$ of replicates required to detect wolves with a probability $P=0.95$ (under the assumption that a valley was occupied) as:

$n_{\min }=\log (1-P) / \log \left(1-p_{m}\right)$.

\section{Manpower and survey costs}

Manpower time was calculated as follows and rounded to full days: For the camera traps and audio recorders, time included equipment deployment in early summer and removal in late autumn on either year, and sorting of wolf images and wolf howls, respectively. For the audio recorder, manpower was calculated based on the 2019 setup. While our personnel already had the adequate knowledge for the above-motioned tasks and we, therefore, did not factor in any training time (or costs), one or two hour training may be required for inexperienced volunteers. For the detection dog, time included daily transects and laboratory time (extraction, PCR, sequencing) to analyse scats at species and individual level. Because the search teams (dog and handlers) used in this study were already-trained professionals, training costs, and time were not included in the calculations. Time required to determine the exact location of camera traps and audio recorders and to plan transects was not noted, but considered to be equivalent for the three methods.
Transportation costs and time were calculated from a common starting point, the city of Bellinzona (Ticino, Switzerland), near the study site. Equipment costs were calculated for a duration between one and 2 years (based on the 2019 setup for the audio recorders). For the detection $\mathrm{dog}$, costs included equipment for the collection of scats and laboratory material (assuming all machinery such as a PCR machine to be readily available). Lodging costs and salaries of personnel involved were not considered, as they are highly variable and dependent on a wide range of conditions including potential use of personnel working on a volunteer basis.

\section{Results}

Based on data collected between 2018 and 2019 with the three survey methods (baseline information), presence of the pack was confirmed in six of the seven valleys. In 2018, the pack was composed of at least four adults and three pups. In 2019 , a minimum of three adults was confirmed but, due to the death of the dominant female at the end of 2018, the pack did not produce pups. For additional baseline information see Supplementary Material S2.

The camera traps were operational an average of 141 (min.: 116, max.: 153) and 140 (min.: 116, max.: 153) days/ camera in 2018 and 2019, respectively. Six and seven cameras photographed wolves during 33 and 23 single days in 2018 and 2019, respectively. Across the two survey years, cameras allowed confirming the presence of wolves in four valleys (i.e. $66 \%$ of the 6 occupied baseline valleys, Table 1 ). In both years, wolves were photographed at least once in every survey month. Pups were photographed by one camera only on four occasions. During 2019 one of the cameras in the Roveredo valley was stolen and data for that valley relies on three cameras only.

The seven audio recorders were operational an average of 94 (min.: 81, max.: 115) and 117 (min.: 66, max.: 144) recording days/recorder in 2018 and 2019, respectively. The additional recorder in the Morobbia valley was operational for 64 and 130 days. We detected wolf howls during only 1 day and with one audio recorder both in 2018 and 2019. As a comparison, the additional audio recorder in the Morobbia valley recorded wolves during 7 and 15 days in 2018 and 2019 , respectively. $95 \%$ of the recorded howls were between the last week of June and mid-August. Across the two survey years, audio recorders allowed confirming the presence of wolves in only one valley ( $17 \%$ compared to the baseline, Table 1).

During the four consecutive field visits, the search team walked $32,31,33$, and 33 of the 35 originally planned 2-km-long sections. The detection dog signalled forty-three scats (32 in 2018 and 11 in 2019), which were subsequently collected. Eleven scats could not be genetically identified 
Table 1 Overview of data collected and survey effort. Numbers are as follows: 2018-2019-2 years combined

\begin{tabular}{llllll}
\hline & Nr. valleys & Nr. adults & Nr. pups & $\begin{array}{l}\text { Survey dura- } \\
\text { tion (weeks) }\end{array}$ & $\begin{array}{l}\text { Data collection } \\
\text { and preparation } \\
\text { (days) }\end{array}$ \\
\hline Baseline & $5-5-6$ & $4-3-\geq 4$ & $3-$ na-na & - & - \\
Camera traps & $3-4-4(66 \%)$ & $4-3-4$ & $3-$ na-na & $22^{2}-22^{2}-44$ & $16^{4}-16^{4}-32$ \\
Audio recorders & $1-1-1(17 \%)$ & $\geq 2-1-\geq 2$ & yes-na-na & $22^{2}-22^{2}-44$ & $17^{5}-17^{5}-34$ \\
Detection dog & $5-2-5(83 \%)$ & $3-2-4^{1}$ & $0-$ na-na & $4^{3}-4^{3}-8$ & $16^{6}-15^{6}-31$ \\
\hline
\end{tabular}

Percentages in brackets refer to the baseline number of valleys occupied across both years

${ }^{1}$ Genetically identified individuals

${ }^{2}$ Equipment placed beginning of June and retrieved end of October

${ }^{3} 2$ weeks in June and 2 in October

${ }^{4} 7$ days to place and 7 days to remove the cameras. 2 days to process pictures (rate of ca. 2.2 pictures/sec for negative pictures)

${ }^{5} 4$ days to place and 4 days to remove the audio recorders. 9 days to process the audio files (rate of ca. $12 \mathrm{~min} /$ audio recorder/night)

${ }^{6} 7$ days for the transects in each of the two yearly visits. 2 days and 1 day in the first and second year, respectively, for lab analyses (rate of ca. $25 \mathrm{~min} / \mathrm{sample}$ ) because they were too old. Of the remaining 32 scats, 27 were genetically assigned to wolf, four to fox (Vulpes vulpes), and one to domestic dog (Canis familiaris). Ten of the 27 wolf scats could be further identified to the individual level. At collection stage in the field, the handler judged four of these five misidentified scats (the four fox and the one dog) as 'highly likely fox scats', based on shape and size, thus potentially reducing to 28 candidate scats the number of needed genetic tests. The search team thus had a wolf identification success rate of $96 \%$ ( 27 of 28 scats). Across the two survey years, detection dogs allowed confirming the presence of wolves in five valleys (83\% compared to the baseline, Table 1).

\section{Pack composition}

In both years, minimum pack size was estimated closest to the baseline information using camera traps (Table 1). Averaged across the 2 years, the detection dogs allowed identifying $71 \%$ of the number of adults identified through camera traps, while audio recorders only identified $\geq 43 \%$ (the ' $\geq$ ' is due to the uncertainty about the exact number of howling wolves detected in 2018; Table 1). As a comparison, the additional camera traps strategically placed in the Morobbia valley did not add any information about pack composition. On the other side, the additional audio recorder placed in the Morobbia valley detected $57-71 \%$ of individuals in the pack. Both camera traps and audio recorders confirmed the presence of pups in 2018, but the number (three pups) could only be determined with camera traps. The dogs did not detect the presence of pups (Table 1).

Halving camera trap survey duration and effort resulted in a $15 \%$ reduction in the ability of the camera traps to return the minimum number of adults in the pack. Halving dog survey duration or effort decreased performance by about $40 \%$ in either case, which corresponded to a detection of about $40 \%$ of the minimum number of adults in the pack. Audio recorders' performance decreased by more than $50 \%$ when survey duration or effort were halved, returning only $21 \%$ of the minimum number of adults in the pack. As a comparison, halving survey duration and effort for the additional audio recorder placed in the Morobbia valley did not decrease its ability to return pack demography.

The DNA analysis successfully identified a reproducing pair and a female in 2018, while in 2019 we identified the same reproducing male and a new female, which we speculate being one of the 2018 pups.

\section{Detection probability and sampling effort}

Survey-method-specific detection probability per replicate was $0.22 \pm 0.04$ (mean $\pm \mathrm{sd}$ ) for the detection $\mathrm{dog}$, $0.20 \pm 0.03$ for the camera traps, and $0.02 \pm 0.01$ for the audio recorders (Table 2). Under the presented sampling design, the probability to detect wolves in a valley where they were present was $0.99,0.71$, and 0.26 using camera traps, detection dogs, and audio recorders, respectively. Any combination of two or three survey methods returned almost a $100 \%$ probability to detect wolves, except when only detection dogs and audio recorders were considered (Table 2). The deployments of four camera traps during 13 weeks, or of one audio recorder during 148 weeks, or a 24-km-long transect with the detection dog were necessary to reach a probability $P=0.95$ that an occupied valley would be recognized as such (Fig. 2, Table 2). 
Table 2 Wolf detection probabilities for three noninvasive survey methods
Fig. 2 Number of replicates required to detect wolves (in a $10 \mathrm{~km}^{2}$ valley assumed to be occupied) with a probability $(P)$. Replicates refer to the number of 2-km-long transects walked with a detection dog and to the number of weeks during which four camera traps, respectively one audio recorder, are operational

\begin{tabular}{llllllll}
\hline & $p_{m}(\mathrm{SD})$ & $P_{m}$ & $n_{\text {min }}$ & $P_{\text {comb }}$ & $P_{\text {comb }}$ & $P_{\text {comb }}$ & $P_{\text {comb }}$ \\
\hline Camera traps & $0.20(0.03)$ & 0.99 & 12 & 1.00 & - & 1.00 & 1.00 \\
Audio recorders & $0.02(0.01)$ & 0.26 & 148 & & 0.79 & - & \\
Detection dog & $0.22(0.04)$ & 0.71 & 12 & - & & 1.00 & \\
\hline
\end{tabular}

$p_{m}$ : Method-specific detection probability per replicate (i.e. 1 week with four and one operational camera traps and audio recorder, respectively, and a 2-km-long transect with the detection $\operatorname{dog} . P_{m}$ : Methodspecific detection probability per valley for a sampling effort of 20 replicates with camera traps, 15 replicates with the audio recorder and 5 replicates with the detection dog. $n_{\min }$ : Minimum number of replicates required to detect wolves with a probability $P=0.95$ (under the assumption that a valley is occupied). $P_{\text {comb }}$ : Effect of the combination of the survey methods on detection probability in an occupied valley

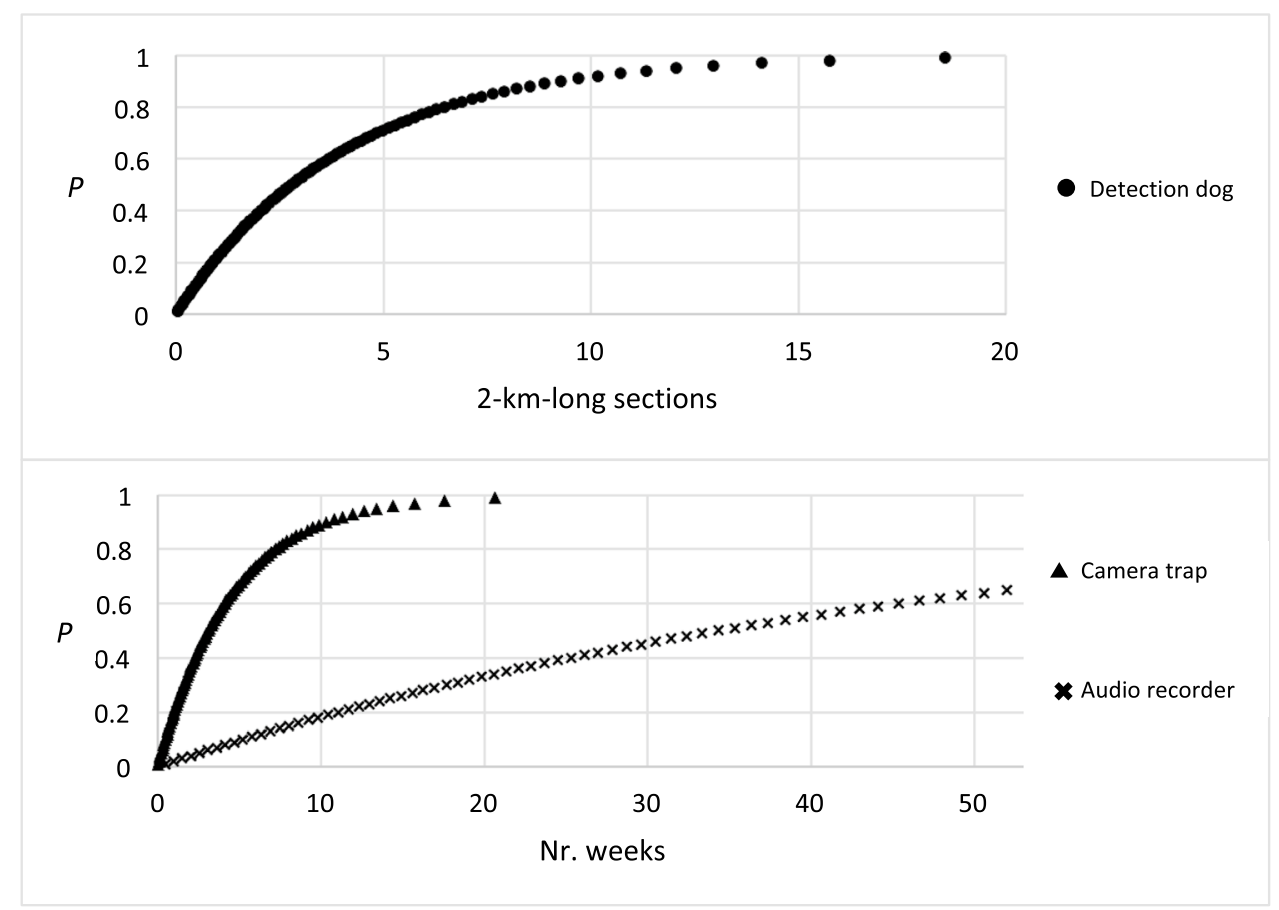

\section{Manpower and survey costs}

The manpower needed for data collection and data preparation was comparable for the three methods, and was just above 30 days across the 2 years (Table 1 ). Over 2 years, the use of audio recorders was about $20 \%$ less expensive than camera trapping (Table 3). While equipment/material costs for the detection dog were low relative to the other two methods, the main costs may stem from the need to use and pay qualified dog handlers and laboratory personnel for DNA extraction and analysis (here not quantified, Table 3).

\section{Discussion}

We compared the performance of three non-invasive survey methods: camera trapping, passive howling, and scat detection dogs, to infer territorial extent and composition of a pack of wolves during recolonisation process in the Swiss Alps. Under the presented survey setup, the camera traps and the scat detection dogs considerably outperformed the audio recorders. However, no method alone was enough to obtain all information that we hoped to collect on pack territorial extent and pack size, presence and number of pups, and identification of single individuals.

Our results confirmed the adequacy of placing one camera trap every $2-2.5 \mathrm{~km}^{2}$ and without prior knowledge of optimal camera trap sites. This aligns with general guidelines for camera trapping of medium-to-large terrestrial vertebrates (TEAM 2011, Rovero et al. 2013). The lack of additional information gained from the cameras strategically placed in the Morobbia valley suggested that a more intensive sampling design (i.e. $>$ four cameras) might not be necessary for a mobile species such as the wolf. To the contrary, given that the probability of detecting wolves in a valley where they were present was almost 1 , a survey shorter than 
Table 3 Expenses for three non-invasive survey methods to monitor wolf presence and pack composition.

\begin{tabular}{|c|c|c|c|c|c|}
\hline & Item description & $\begin{array}{l}\text { Price/unit } \\
\text { (CHF) }\end{array}$ & Quantity & Tot for 1 st year & $\begin{array}{l}\text { Addition } \\
\text { for } 2 \text { nd } \\
\text { year }\end{array}$ \\
\hline \multirow[t]{5}{*}{ Camera trap } & SanDisk Extreme Pro $32 \mathrm{~GB}^{1}$ & 14 & 28 & 392 & - \\
\hline & 16-pack Duracell AA ${ }^{1}$ & 10 & 14 & 140 & 140 \\
\hline & Camera trap ${ }^{2}$ & 299 & 28 & 8372 & - \\
\hline & Transportation & 20 & 14 & 280 & 280 \\
\hline & & & CHF & 9184 & 9604 \\
\hline \multirow[t]{5}{*}{ Audio recorder } & SanDisk Extreme Pro $64 \mathrm{~GB}^{1}$ & 16 & 28 & 448 & - \\
\hline & Spypoint Kit (Battery and Solar) ${ }^{1}$ & 150 & 7 & 1050 & - \\
\hline & Song Meter SM4 ${ }^{3}$ & 850 & 7 & 5950 & - \\
\hline & Transportation & 20 & 8 & 160 & 160 \\
\hline & & & CHF & 7608 & 7768 \\
\hline \multirow[t]{4}{*}{ Detection dog } & Transportation & 20 & 14 & 280 & 280 \\
\hline & Laboratory costs: species level ${ }^{4}$ & 20 & $32^{5}$ & 640 & 220 \\
\hline & Additional lab costs: ind. level ${ }^{4}$ & 13 & $21^{5}$ & 273 & 78 \\
\hline & & & CHF & 1193 & 1771 \\
\hline
\end{tabular}

Total expenses for each method are highlighted in bold

${ }^{1}$ www.amazon.com

2 www.cuddeback.com

${ }^{3}$ www.wildlifeacoustics.com

${ }^{4}$ Costs based on figures from the Conservation Genetics Group of the Senckenberg Nature Research Society (Germany)

${ }^{5}$ Thirty-two scats in 2018 of which 21 were wolf scats, which were further investigated to individual level. Eleven scats in 2019 of which 6 were wolf scats, which were further investigated to individual level the current setup or the deployment of less cameras may be suggested and traps relocated to sample a larger area. Such a high detection probability may be partly influenced by the impervious terrain and steep slopes that encouraged wolves to often use hiking trails.

Our study confirmed the period July-August as howling peak activity, as previously reported (Gazzola et al. 2002; Nowak et al. 2007; Passilongo et al. 2010). As a consequence, extending passive howling survey duration may not be a viable approach to increase survey performance, for it would expand sampling effort during sub-optimal periods of the year. Matching the performance of the camera traps and scat detection dogs may only be obtained by increasing the number of audio recorders. For instance, similar wolf detectability has been found when a comparable number of camera traps and audio recorders were deployed (Garland et al. 2020). This would, however, inflate budget and data processing time for the audio recorders making camera traps preferred over them. This also in light of the camera versatility for broad spectrum species biodiversity surveys (Wearn and Glover-Kapfer 2019). The significantly better performance of the audio recorder strategically placed in the Morobbia valley suggested that audio recorders may be more adequate to monitor an established population where knowledge of optimal sites is available, rather than for monitoring single packs at the beginning of the recolonisation process into historical range for which little information is available. For instance, breeding burrows or rendez-vous sites have been recognized to be optimal sites to monitor wolf populations using multiple survey methods (Brennan et al. 2013; Ausband et al. 2014). Owing to its function (among others) for inter pack communication (Harrington and Mech 1979), howling activity may be reduced, and audio recorders less adequate, in the absence of neighbouring packs. Despite we placed audio recorders at vantage points; valley topology, the wind typical of mountainous regions, and attenuation due to vegetation may have substantially reduced detection (Garland et al. 2020) below the proposed $>3 \mathrm{~km}$ radius (Suter et al. 2017) resulting in some "blind zones" thus contributing to limited detection.

While 10-km-long detection dog transects were adequate to infer pack territorial extent and composition and to match data from the camera traps, reduction in either survey duration or effort below the presented survey setup may be undesirable. Where possible, transects $>20 \mathrm{~km}$ should be walked within an area of about $10 \mathrm{~km}^{2}$ to ensure detection of wolves, if they are present. Beside the natural imperfect detection success, we hypothesise two reasons why the dog did not detect any of the pups born in 2018. Pups may have died before the October visit. During their first 6 months of their life, pups are still morphologically and acoustically distinguishable from adults; the last confirmed record of pups 
from camera traps and audio recorders was in September. In the Alps pups are typically born in June and could not have been detected by the dog during the May/June visit. Alternatively, pups may defecate less than adults at noticeable locations along hiking trails (Vilà et al. 1994), decreasing detection. We based information on the pack's territorial extent on both genetically confirmed samples and on samples too old for genetic analysis but identified as likely wolf (ten scats) by the research team. This appeared a justifiable approach given the observed high accuracy $(97 \%)$ of the search team in distinguishing wolf scats from others. Similar levels of high accuracy have been observed elsewhere for a variety of target species (Smith et al. 2001; Smith et al. 2003; Cristescu et al. 2015). The accuracy of the search team in detecting wolf scats against other species makes it a suitable method to timely (each visit lasted only two weeks) obtain accurate information on wolf presence and distribution. This was in clear contrast with the much longer (4 months) survey duration with camera traps and audio recorders. Using a survey effort comparable to ours (4 sites each of: $64 \mathrm{~km}^{2}$ with 16 camera traps placed during 7-8 weeks and two detection dogs searching for a period of time $\geq 5$ days) Clare et al. (2015) estimated that 2 days of dog survey in a $4 \mathrm{~km}^{2}$ area had similar detection probability for bobcats (Lynx rufus) than a single camera placed during 7-8 weeks. Long et al. (2007a, b) found that camera traps deployed for only 14 days had a substantially lower success than dogs in detecting black bear (Ursus americanus), fisher (Martes pennanti), and bobcat. While the design of Long and colleagues was different from ours (they placed one camera with attractant within every 2-km long diamond transect, so roughly 1 camera $/ \mathrm{km}^{2}$ ), and so were the target species, both studies support results from our study and suggest that camera trapping efforts should last a few months to be comparable to scat detection dogs.

While we did not attempt to quantify lodging and salary costs, a few considerations can be made. Because duration of data collection and preparation was similar among the three methods (Table 1) such costs may cancel one other out if qualified personnel has to be hired for each method. Personnel working on a volunteer basis may, however, be used to conduct part of the camera trapping and audio-recording work potentially reducing costs. On the other hand, hiring a qualified detection team and laboratory technician has been shown to be financially demanding (Long et al. 2007a, b; Clare et al. 2015, Hollerbach L. unpubl. data). Such costs may only be partly compensated by the limited funds (compared to the other methods) that need be allocated to laboratory costs (this study, Hollerbach L. unpubl. data). Thus, despite under the presented setup the use of a scat detection dog can be used as a reliable stand-alone method, owing to its associated costs, only a short and informed deployment may be feasible. Targeted transects with detection dogs may, for instance, be planned in correspondence of areas of high wolf activity to increase scat detection and allow individual identification through DNA analysis. As we used professional handlers and already-trained dogs, we were not able to quantify training time and costs. Training a dog has, however, been shown to require anywhere between 2-3 to 6-12 months depending on the circumstances and tasks (Robertson and Fraser 2009, Mathews et al. 2013). Such additional time and the related costs should be taken into considerations if training an inexperienced dog is the option of choice. Particularly during the recolonisation process, the traceability of the movements of single individuals is fundamental to understand patterns of new packs formation either through pack splitting, budding, local emigration, or through immigration from a (separated) source population (Jędrzejewski et al. 2004; Mech and Boitani 2010; Bauduin et al. 2020). As this knowledge is crucial for targeted management and conservation practices (Behr et al. 2017), we advocate for the use of detection dogs and scat analysis or any other method that allows reliably identifying single individuals. Some very recent developments of facial recognition algorithms may soon facilitate individual recognition based on camera trapping also for species that lack unique pelage markings (Clapham et al. 2020).

Our study and inferences suffer from the limited sample size (one pack) — and consequently from the limited number of devices deployed and transects walked-and from the death of the dominant female in the second year of the survey. For instance, the absence of the dominant female may have been partly responsible for the decrease in the number of days with positive wolf pictures and in the number of found scats between 2018 and 2019. We nonetheless believe that these scenarios are well representative of any recolonisation process characterized by few, small packs scattered across the landscape and, therefore, valuable for the purpose of the present study. We, however, suggest further studies to be conducted to help developing and refining methods to timely and accurately follow species range expansion and contraction and for biodiversity monitoring, conservation, and management. Additionally, further investigations may also consider the possible effects of false identification, which may play a crucial role where numbers are low as at the boundary of populations. For instance, blurred camera trap pictures (mainly at night-time depending on flash type) may not always allow unmistakably recognition of the target species (Rovero et al. 2013).

Information on performance and financial costs of different survey methods is essential for planning cost-effective monitoring schemes and management plans (Bennett et al. 2020). We showed that the three survey methods used were suitable to detect the presence of a single pack of wolves during the recolonisation process, despite substantial differences in performance and costs. No method alone returned 
all information that we hoped to collect, which was best obtained through a combination of two methods. Based on our results, we suggest the combined use of camera traps and scat detection dogs as best suited and most cost-effective for the monitoring of wolf packs during recolonisation into historical ranges.

Supplementary Information The online version contains supplementary material available at https://doi.org/10.1007/s42991-021-00167-6.

Acknowledgements We thank the authorities of the Cantons of Ticino and Graubünden for allowing and facilitating this research and for helping with field logistics and equipment. Particular thanks go to the game wardens Alex Ambrosini, Thomas Romanski, Stefano Beltrami, Nicola de Tann, and Stefano Fasani. We thank the Foundation KORA for providing additional camera traps and particularly Ralph Manz for helping in the field. Special thanks to Lea Wirk and Catriona Blum-Rérat for assistance with scat detection dogs and to Luc LeGrand for the search through the SCOPUS database. We thank Carsten Nowak and his team at the Conservation Genetics Section of Senckenberg Research Institute for the analysis of the scat samples at the species level and Luca Fumagalli and his team at the Laboratory for Conservation Biology at the University of Lausanne for genetic identification of individual wolves. This study was possible through funds from the Albert-Heim Foundation, the Bernd-Thies Foundation, and the University of Zurich.

Funding Open Access funding provided by Universität Zürich.

\section{Declarations}

Conflict of interest On behalf of all authors, the corresponding author states that there is no conflict of interest.

Open Access This article is licensed under a Creative Commons Attribution 4.0 International License, which permits use, sharing, adaptation, distribution and reproduction in any medium or format, as long as you give appropriate credit to the original author(s) and the source, provide a link to the Creative Commons licence, and indicate if changes were made. The images or other third party material in this article are included in the article's Creative Commons licence, unless indicated otherwise in a credit line to the material. If material is not included in the article's Creative Commons licence and your intended use is not permitted by statutory regulation or exceeds the permitted use, you will need to obtain permission directly from the copyright holder. To view a copy of this licence, visit http://creativecommons.org/licenses/by/4.0/.

\section{References}

Ausband DE, Rich LN, Glenn EM, Mitchell MS, Zager P, Miller DAW, Waits LP, Ackerman BB, Mack CM (2014) Monitoring gray wolf populations using multiple survey methods. J Wildl Manag 78:335-346

Bauduin S, Grente O, Santostasi NL, Ciucci P, Duchamp C, Gimenez O (2020) An individual-based model to explore the impacts of lesser-known social dynamics on wolf populations. Ecol. Modell. 433:109209

Bauer H, Chapron G, Nowell K, Henschel P, Funston P, Hunter LTB, Macdonald DW, Packer C (2015) Lion (Panthera leo) populations are declining rapidly across Africa, except in intensively managed areas. Proc Natl Acad Sci USA 112:14894-14899
Becker MS, Durant SM, Watson FGR, Parker M, Gottelli D, Msoka J, Droge E, Nyirenda M, Schuette P, Dunkley S et al (2017) Using dogs to find cats: detection dogs as a survey method for wideranging cheetah. J Zool 302:184-192

Behr DM, Ozgul A, Cozzi G (2017) Combining human acceptance and habitat suitability in a unified socio-ecological suitability model: a case study of the wolf in Switzerland. J Appl Ecol 54:1919-1929

Bennett EM, Hauser CE, Moore JL (2020) Evaluating conservation dogs in the search for rare species. Conserv Biol 34:314-325

Brennan A, Cross PC, Ausband DE, Barbknecht A, Creel S (2013) Testing automated howling devices in a wintertime wolf survey. Wildl Soc Bull 37:389-393

Chapron G, Kaczensky P, Linnell JDC, von Arx M, Huber D, Andrén H, López-Bao JV, Adamec M, Álvares F, Anders O, Balčiauskas L, Balys V, Bedő P, Bego F, Blanco JC, Breitenmoser U, Brøseth H, Bufka L, Bunikyte R, Ciucci P, Dutsov A, Engleder T, Fuxjäger C, Groff C, Holmala K, Hoxha B, Iliopoulos Y, Ionescu O, Jeremić J, Jerina K, Kluth G, Knauer F, Kojola I, Kos I, Krofel M, Kubala J, Kunovac S, Kusak J, Kutal M, Liberg O, Majić A, Männil P, Manz R, Marboutin E, Marucco F, Melovski D, Mersini K, Mertzanis Y, Mysłajek RW, Nowak S, Odden J, Ozolins J, Palomero G, Paunović M, Persson J, Potočnik H, Quenette P-Y, Rauer G, Reinhardt I, Rigg R, Ryser A, Salvatori V, Skrbinšek T, Stojanov A, Swenson JE, Szemethy L, Trajçe A, TsingarskaSedefcheva E, Váňa M, Veeroja R, Wabakken P, Wölfl M, Wölfl S, Zimmermann F, Zlatanova D, Boitani L (2014) Recovery of large carnivores in Europe's modern human-dominated landscapes. Science 346:1517-1519

Clapham M, Miller ED, Nguyen M, Darimont CT (2020) Automated facial recognition for wildlife that lack unique markings: a deep learning approach for brown bears. Ecol Evol 10:12883-12892

Clare JDJ, Anderson EM, MACfarland DM (2015) Comparing the costs and detectability of bobcat using scat-detecting dog and remote camera surveys in central Wisconsin. Wildl Soc Bull 39:210-217

Cozzi G, Broekhuis F, McNutt JW, Schmid B (2013) Density and habitat use of lions and spotted hyenas in northern Botswana and the influence of survey and ecological variables on call-in survey estimation. Biodivers Conserv 22:2937-2956

Cristescu RH, Foley E, Markula A, Jackson G, Jones D, Frère C (2015) Accuracy and efficiency of detection dogs: a powerful new tool for koala conservation and management. Sci Rep 5:8349

David Mech L, Boitani L (2010) Wolves: behavior, ecology, and conservation. University of Chicago Press, Chicago

Dufresnes C, Remollino N, Stoffel C, Manz R, Weber J-M, Fumagalli $\mathrm{L}$ (2019) Two decades of non-invasive genetic monitoring of the grey wolves recolonizing the Alps support very limited dog introgression. Sci Rep 9:148

Durant SM, Mitchell N, Groom R, Pettorelli N, Ipavec A, Jacobson AP, Woodroffe R, Böhm M, Hunter LTB, Becker MS, Broekhuis F, Bashir S, Andresen L, Aschenborn O, Beddiaf M, Belbachir F, Belbachir-Bazi A, Berbash A, de Matos B, Machado I, Breitenmoser C, Chege M, Cilliers D, Davies-Mostert H, Dickman AJ, Ezekiel F, Farhadinia MS, Funston P, Henschel P, Horgan J, de Iongh HH, Jowkar H, Klein R, Lindsey PA, Marker L, Marnewick K, Melzheimer J, Merkle J, Msoka J, Msuha M, O’Neill H, Parker M, Purchase G, Sahailou S, Saidu Y, Samna A, Schmidt-Küntzel A, Selebatso E, Sogbohossou EA, Soultan A, Stone E, van der Meer E, van Vuuren R, Wykstra M, Young-Overton K (2017) The global decline of cheetah Acinonyx jubatus and what it means for conservation. Proc Natl Acad Sci USA 114:528-533

Funston PJ, Frank L, Stephens T, Davidson Z, Loveridge A, Macdonald DM, Durant S, Packer C, Mosser A, Ferreira SM (2010) Substrate and species constraints on the use of track incidences to estimate African large carnivore abundance. J Zool 281:56-65 
Galaverni M, Palumbo D, Fabbri E, Caniglia R, Greco C, Randi E (2012) Monitoring wolves (Canis lupus) by non-invasive genetics and camera trapping: a small-scale pilot study. Eur J Wildl Res 58:47-58

Garland L, Crosby A, Hedley R, Boutin S, Bayne E (2020) Acoustic vs. photographic monitoring of gray wolves (Canis lupus): a methodological comparison of two passive monitoring techniques. Can J Zool 98:219-228

Gazzola A, Avanzinelli E, Mauri L, Scandura M, Apollonio M (2002) Temporal changes of howling in south European wolf packs. Ital J Zool 69:157-161

Harrington FH, David Mech L (1979) Wolf howling and its role in territory maintenance. Behaviour 68:207-249

Harrington FH, Mech LD (1982) An analysis of howling response parameters useful for wolf pack censusing. J Wildl Manag 46:686-693

Hatlauf J, Böcker F, Wirk L, Collet S, Schley L, Szabó L, Hackländer K, Heltai M (2020) Jackal in hide: detection dogs show first success in the quest for golden jackal (Canis aureus) scats. Mammal Res. https://doi.org/10.1007/s13364-020-00537-4

Hollerbach L, Heurich M, Reiners TE, Nowak C (2018) Detection dogs allow for systematic non-invasive collection of DNA samples from Eurasian lynx. Mamm Biol 90:42-46

Hunziker M, Hoffmann CW, Wild-Eck S (2001) Die Akzeptanz von Wolf, Luchs und Stadtfucs-Ergebnisse einer gesamtschweizerisch-repräsentativen Umfrage. For Snow Landsc Res 76:301-326

Hurt A, Smith DA (2009) Conservation Dogs. In: Helton, WS (ed) Canine Ergonomics: The Science of Working Dogs. CRC Press, NW, pp175-194

Kéry M, Schaub M (2012) Bayesian Population Analysis using WinBUGS: A Hierarchical Perspective. Academic Press

Jacobson AP, Gerngross P, Lemeris JR Jr, Schoonover RF, Anco C, Breitenmoser-Würsten C, Durant SM, Farhadinia MS, Henschel P, Kamler JF, Laguardia A, Rostro-García S, Stein AB, Dollar L (2016) Leopard (Panthera pardus) status, distribution, and the research efforts across its range. PeerJ 4:e1974

Jędrzejewski W, Schmidt K, Jędrzejewska B, Theuerkauf J, Kowalczyk R, Zub K (2004) The process of a wolf pack splitting in Białowieża Primeval Forest. Acta Theriologica, Poland. https:// doi.org/10.1007/bf03192527

Karanth KU, Nichols JD (1998) Estimation of tiger dnsities in India using photographic captures and recaptures. Ecology 79:2852-2862

Long RA, Donovan TM, Mackay P, Zielinski WJ, Buzas JS (2007a) Comparing scat detection dogs, cameras, and hair snares for surveying carnivores. J Wildl Manag 71:2018-2025

Long RA, Donovan TM, Mackay P, Zielinski WJ, Buzas JS (2007b) Effectiveness of scat detection dogs for detecting forest carnivores. J Wildl Manag 71:2007-2017

MacKenzie DI, Nichols JD, Lachman GB, Droege S, Royle AA, Langtimm CA (2002) Estimating site occupancy rates when detection probabilities are less than one. Ecology 83:2248-2255

Matthews F, Swindells M, Coodhgead R, August TA, Hardman P, Linton DM, Hosken DJ (2013) Effectiveness of search dogs compared with human observers in locating bat carcasses at wind-turbine sites: a blinded randomized trial. Wild Soc Bul 37:34-40

Mattioli L, Canu A, Passilongo D, Scandura M, Apollonio M (2018) Estimation of pack density in grey wolf (Canis lupus) by applying spatially explicit capture-recapture models to camera trap data supported by genetic monitoring. Front Zool 15:38

Meek PD, Ballard GA, Sparkes J, Robinson M, Nesbitt B, Fleming PJS (2019) Camera trap theft and vandalism: occurrence, cost, prevention and implications for wildlife research and management. Remote Sens Ecol Conserv 5:160-168

Milanesi P, Breiner FT, Puopolo F, Holderegger R (2017) European human-dominated landscapes provide ample space for the recolonization of large carnivore populations under future land change scenarios. Ecography 40:1359-1368

Nowak S, Jędrzejewski W, Schmidt K, Theuerkauf J, Mysłajek RW, Jędrzejewska B (2007) Howling activity of free-ranging wolves (Canis lupus) in the Białowieża Primeval Forest and the Western Beskidy Mountains (Poland). J Ethol 25:231-237

Oliveira ML, Duarte JMB (2013) Amplifiability of mitochondrial, microsatellite and amelogenin DNA loci from fecal samples of red brocket deer Mazama americana (Cetartiodactyla, Cervidae). Genet Mol Res 12:44-52

Passilongo D, Mattioli L, Bassi E, Szabó L, Apollonio M (2015) Visualizing sound: counting wolves by using a spectral view of the chorus howling. Front Zool 12:22

Passilongo D, Buccianti A, Dessi-Fulgheri F, Gazzola A, Zaccaroni M, Apollonio M (2010) The acoustic structure of wolf howls in some eastern Tuscany (Central Italy) free ranging packs. Bioacoustics 19:159-175

Peters RP, Mech LD (1975) Scent-Marking in Wolves: Radio-tracking of wolf packs has provided definite evidence that olfactory sign is used for territory maintenance and may serve for other forms of communication within the pack as well. Am Sci 63:628-637

Reed SE, Bidlack AL, Hurt A, Getz WM (2011) Detection distance and environmental factors in conservation detection dog surveys. J Wildl Manag 75:243-251

Rich LN, Miller DAW, Robinson HS, McNutt JW, Kelly MJ (2016) Using camera trapping and hierarchical occupancy modelling to evaluate the spatial ecology of an African mammal community. J Appl Ecol 53:1225-1235

Robertson H, Fraser J (2009) Use of trained dogs to determine the age structure and conservation status of kiwi Apteryx spp. Popul Bird Conserv Int 19:121-129

Roder S, Biollaz F, Mettaz S, Zimmermann F, Manz R, Kéry M, Vignali S, Fumagalli L, Arlettaz R, Braunisch V (2020) Deer density drives habitat use of establishing wolves in the Western European Alps. J Appl Ecol 57:995-1008

Root-Gutteridge H, Bencsik M, Chebli M, Gentle LK, Terrell-Nield C, Bourit A, Yarnell RW (2014) Improving individual identification in captive Eastern grey wolves (Canis lupus lycaon) using the time course of howl amplitudes. Bioacoustics 23:39-53

Rovero F, Zimmermann F, Berzi D, Meek P (2013) “ Which camera trap type and how many do I need?" A review of camera features and study designs for a range of wildlife research applications. Hystrix 24:148-156

Rutledge LY, Holloway JJ, Patterson BR, White BN (2009) An improved field method to obtain DNA for individual identification from Wolf Scat. J Wildl Manag 73:1430-1435

Smith DA, Ralls K, Cypher BL, Maldonado JE (2005) Assessment of scat-detection dog surveys to determine kit fox distribution. Wildl Soc Bull 33:897-904

Smith DA, Ralls K, Hurt A, Adams B, Parker M, Davenport B, Smith MC, Maldonado JE (2003) Detection and accuracy rates of dogs trained to find scats of San Joaquin kit foxes (Vulpes macrotis mutica). Anim Conserv 6:339-346

Stępniak KM, Niedźwiecka N, Szewczyk M, Mysłajek RW (2020) Scent marking in wolves Canis lupus inhabiting managed lowland forests in Poland. Mammal Res 65:629-638

Stiftung KORA (2020) 25 Jahre Wolf in der Schweiz - Eine Zwischenbilanz. KORA-Bericht Nr. 91, 80

Suter SM, Giordano M, Nietlispach S, Apollonio M, Passilongo D (2017) Non-invasive acoustic detection of wolves. Bioacoustics 26:237-248

TEAM Network (2011) Terrestrial Vertebrate Protocol Implementation Manual, v. 3.1.Tropical Ecology, Assessment and Monitoring Network, Center for Applied BiodiversityScience, Conservation International, Arlington, VA, USA 
Vilà C, Urios V, Castroviejo J (1994) Use of faeces for scent marking in Iberian wolves (Canis lupus). Can J Zool 72:374-377

Vynne C, Skalski JR, Machado RB (2011) Effectiveness of scat-detection dogs in determining species presence in a tropical savanna landscape. Conserv Biol 25:154-162

Wasser SK, Keim JL, Taper ML, Lele SR (2011) The influences of wolf predation, habitat loss, and human activity on caribou and moose in the Alberta oil sands. Front Ecol Environ 9:546-551

Wearn OR, Glover-Kapfer P (2019) Snap happy: camera traps are an effective sampling tool when compared with alternative methods. R Soc Open Sci 6:181748
Publisher's Note Springer Nature remains neutral with regard to jurisdictional claims in published maps and institutional affiliations. 